\title{
Enrichment and characterization of cancer stem cells from a human non-small cell lung cancer cell line
}

\author{
CHANGHONG ZHAO $^{1}$, SARRA SETRERRAHMANE ${ }^{1}$ and HANMEI XU ${ }^{1,2}$ \\ ${ }^{1}$ The Engineering Research Center of Peptide Drug Discovery and Development; ${ }^{2}$ State Key Laboratory \\ of Natural Medicines, Ministry of Education, China Pharmaceutical University, Nanjing, Jiangsu 210009, P.R. China
}

Received April 15, 2015; Accepted July 7, 2015

DOI: $10.3892 /$ or.2015.4163

\begin{abstract}
Tumor cells from the same origin comprise different cell populations. Among them, cancer stem cells (CSCs) have higher tumorigenicity. It is necessary to enrich CSCs to determine an effective way to suppress and eliminate them. In the present study, using the non-adhesive culture system, tumor spheres were successfully generated from human A549 non-small cell lung cancer (NSCLC) cell line within 2 weeks. Compared to A549 adherent cells, sphere cells had a higher self-renewal ability and increased resistance to cytotoxic drugs. Sphere cells were more invasive and expressed stem cell markers including octamer-binding transcription factor 4 (Oct4) and sex-determining region Y-box 2 (Sox2) at high levels. CD133, a disputed marker of lung CSCs, was also upregulated. Tumor sphere cells showed higher tumorigenic ability in vivo, indicating that more CSCs were enriched in the sphere cells. More blood vessels were formed in the tumor generated by sphere cells suggesting the interaction between CSCs and blood vessel. A reliable model of enriching CSCs from the human A549 NSCLC cell line was established that was simple and cost-effective compared to other methods.
\end{abstract}

\section{Introduction}

Cancer stem cells (CSCs) have been found in various tumors including breast, gastric and colon, as well as lung cancer (1). They are the driving force of tumor progression, recurrence and drug resistance $(2,3)$. CSCs and non-CSCs are two distinctive populations with different properties $(4,5)$. CSCs constitute only a small fraction of tumor cells, however, establishing a method to effectively and economically enrich CSCs may be useful to gain a better understanding of CSCs.

Correspondence to: Professor Hanmei Xu, The Engineering Research Center of Peptide Drug Discovery and Development, China Pharmaceutical University, 24 Tongjia Xiang, Nanjing, Jiangsu 210009, P.R. China

E-mail: 13913925346@126.com

Key words: cancer stem cells, human non-small cell lung cancer, non-adhesive culture, isolation, characterization
There is controversy over the markers of lung CSCs. Eramo et al reported that the tumorigenic cells in human lung cancer were a rare undifferentiated cell population expressing CD133 (6). Meng et al reported that both CD133+ and CD133 subpopulations of A549 and H446 cells contained CSCs (7). Cui et al found that CD133 may be used as a marker for CSCs in $\mathrm{H} 446$ cells but not in A549 cells (8). Additionally, based on a higher expression of ATP-binding cassette (ABC) transporters and higher activity of aldehyde dehydrogenase (ALDH) in CSCs, side population (SP) and $\mathrm{ALDH}^{\text {high }}$ population are also enriched with lung CSCs (9). However, none of the methods mentioned above is used exclusively to isolate lung CSCs, emphasizing the need to define more specific markers (10).

CSCs can be enriched in the spheres formed after culturing in the serum-free medium supplemented with mitogens such as epidermal growth factor (EGF) and basic fibroblast growth factor (bFGF) (11). However, this process is usually timeconsuming and inefficient. Recently, a new method known as 'The Modified Non-Adhesive Culture System', which improved these drawbacks, was used to isolate CSCs from the human oral squamous cell carcinoma cell lines (SAS and OECM-1) and human cervical carcinoma cell line (HeLa) $(12,13)$. However, whether this isolation method can be applied to lung cancer remains to be determined. In the present study, the nonadhesive culture system was used to generate tumor spheres from the A549 cell line. The CSCs characteristics of isolated sphere cells were verified in vitro and in vivo. A reliable model of enriching CSCs from A549 in vitro was established that may be used in the selection of new drugs targeting lung CSCs.

\section{Materials and methods}

Reagents. The A549 human non-small cell lung cancer (NSCLC) cell line was obtained from the Shanghai Cell Biology Institute of the Chinese Academy of Sciences (Shanghai, China). The antibodies against CD31 (sc-1506), Oct4 (sc-5279) and Sox 2 (sc-17320) were purchased from Santa Cruz Biotechnology, Inc. (Dallas, TX, USA). The FITC-labeled rabbit anti-mouse IgG antibody (ab97045) and the Cy5-labeled donkey anti-goat IgG antibody (ab6566) were purchased from Abcam (Cambridge, MA, USA).

Cell culture. A549 cells were maintained in RPMI-1640 medium (Gibco-Life Technologies, Carlsbad, CA, USA) 
supplemented with $10 \%$ fetal bovine serum (FBS), penicillin $(100 \mathrm{U} / \mathrm{ml})$ and streptomycin $(100 \mu \mathrm{g} / \mathrm{ml})$ in a humidified atmosphere of $5 \% \mathrm{CO}_{2}$ at $37^{\circ} \mathrm{C}$.

Tumor sphere formation and culture. Tumor spheres were formed in the modified non-adhesive culture system reported previously by Chen et al (13). Briefly, parental A549 adherent cells were dissociated with trypsin into single-cell suspension and seeded in a $10-\mathrm{cm}$ cell culture dish coated with a thin film of $1.2 \%$ agarose (dissolved in deionized water) at the density of $8 \times 10^{4}$ cells/dish. Until tumor spheres were formed, the culture medium was changed every other day during the incubation period.

Limiting dilution analysis (LDA) and MTT assay. The 96-well cell culture plates were made non-adhesive for cells by coating with agarose. Parental adherent cells and tumor spheres were trypsinized and seeded at serial concentrations. Cultures were maintained for a week and scored for wells that had no spheres. The results were processed using the web-based extreme LDA (ELDA) software (http://bioinf.wehi.edu.au/software/elda/). The experiments were repeated three times independently. MTT assay was performed as reported in a previous study (12).

$R T-P C R$. Total RNA $(1 \mu \mathrm{g})$ was used as a template for the synthesis of cDNA using a RevertAid First Strand cDNA Synthesis kit (Thermo Fisher Scientific, Beijing, China) following the manufacturer's instructions. From the $5^{\prime}$ to the $3^{\prime}$ end, the sequence of primers used in the reactions was as follows: Oct4 forward, GAAAGCGAACCAGTATCGAGAAC and reverse, CCCCTGAGAAAGGAGACCCA; Sox2 forward, GGTTACCTCTTCCTCCCACTCC and reverse, CCСТCCC ATTTCCCTCGTTT; CD133 forward, GCATTGGCATCTT CTATGGTT and reverse, CGCCTTGTCCTTGGTAGTGT; and GAPDH forward, CGGATTTGGTCGTATTGGG and reverse, CTGGAAGATGGTGATGGGATT.

Cell invasion assay. The cell invasion assay was performed using 24 Transwell chambers (Corning Inc., Corning, NY, USA) as previously described (14). The single cells were suspended in serum-free RPMI-1640 medium at the concentration of $3 \times 10^{5}$ cells $/ \mathrm{ml}$. Cell suspension $(150 \mu \mathrm{l})$ was loaded into the upper chamber insert coated with Matrigel while the lower chamber was loaded with $500 \mu$ l RPMI-1640 with $10 \%$ FBS. After being cultured in the incubator for $48 \mathrm{~h}$, the cells in the upper chamber were removed with a cotton swab. The lower chamber filter was fixed with $4 \%$ paraformaldehyde and stained with crystal violet. The cells that migrated to the lower side of the membrane were viewed under an inverted microscope.

Immunohistochemistry (IHC) and immunofluorescence staining (IFS). Tumors or spheres were fixed in $4 \%$ formalin and embedded in paraffin. IHC was carried out as previously described (13). For the quantification of microvessel density (MVD), any endothelial cell cluster immunoreactive for CD31, clearly separated from adjacent tumor cells, was considered a countable microvessel. Microvessels were quantified in three random fields (magnification, $\mathrm{x} 200$ ) within the areas of high-density staining. For the IFS staining of spheres, after blocking in PBS containing 5\% bovine serum albumin (BSA), slides were incubated with primary antibodies overnight at $4^{\circ} \mathrm{C}$. After being washed with PBS, the slides were incubated with the secondary antibody for $30 \mathrm{~min}$ at $37^{\circ} \mathrm{C}$. DAPI was then added for nuclear staining. An Axio Vert A1 inverted fluorescence microscope was used to capture the images.

Oil red $O$ staining. Fresh frozen tumor tissues were cut (5-10 $\mu \mathrm{m})$ and mounted on slides. The slides were air-dried and maintained for $60 \mathrm{~min}$ at room temperature and fixed in cold formalin for $15 \mathrm{~min}$. After being air-dried for another $60 \mathrm{~min}$, the slides were placed in absolute propylene glycol for $5 \mathrm{~min}$ and then stained in $0.5 \%$ Oil red $\mathrm{O}$ solution for $10 \mathrm{~min}$ at $60^{\circ} \mathrm{C}$. The slides were placed in $85 \%$ propylene glycol solution for $2 \mathrm{~min}$ and rinsed with distilled water. The slides were subsequently stained in hematoxylin and mounted.

In vivo tumorigenicity study. Experiments were performed as per the Guide for the Care and Use of Laboratory Animals. Mice were kept at $25^{\circ} \mathrm{C}, 50 \%$ humidity, in an air-conditioned environment under a 12-h dark/light cycle. The cell suspension $(100 \mu \mathrm{l})$ was injected subcutaneously into the right flank of 6 -week-old BALB/c nude mice at the dose of $1 \times 10^{3}, 1 \times 10^{4}$ and $1 \times 10^{5}$ cells. At 8 weeks after inoculation, the mice were euthanized under anesthesia and the tumors removed and measured.

Statistical analysis. Statistical results were analyzed using SPSS 13.0 statistical software. The significance of difference between two samples of the same group were analyzed using the t-test. The result was considered statistically significant when $\mathrm{P}<0.05$. $\mathrm{P}<0.01$ was considered to indicate a statistically highly significant result.

\section{Results}

Morphology of tumor spheres. A549 tumor spheres were formed after incubation under the non-adhesive culture condition. Compared to parental A549 adherent cells (Fig. 1A), the suspended spheres were cluster of cells that had an oval or round shape (Fig. 1B). The diameter of spheres ranged from 30 to $250 \mu \mathrm{m}$; the diameter of $65.93 \%$ spheres was between 100 and $200 \mu \mathrm{m} ; 22.95 \%$ spheres were $<100 \mu \mathrm{m}$, while the remaining $11.12 \%$ spheres were $>200 \mu \mathrm{m}$ (Fig. 1C). Spheres with a diameter $>200 \mu \mathrm{m}$ may result from the fusion between two small individual spheres based on observation.

The self-renewal potential of sphere cells is higher than that in adherent cells. LDA was used to compare the sphere-forming ability of parental adherent cells and tumor sphere cells cultured under the non-adhesive condition. Data analysis with ELDA software showed that, on average, the frequency of sphere-initiating cells was 1 in 24 for tumor spheres but 1 in 140 for adherent cells (Fig. 1D). In contrast to adherent cells, the spheres contained a 5.83-fold higher frequency of sphere-initiating cells contributing to its higher self-renewal potential.

Sphere cells are less sensitive to chemotherapy drugs than adherent A549 cells. Many tumors develop drug resistance during treatment. The reason is that CSCs can survive even 

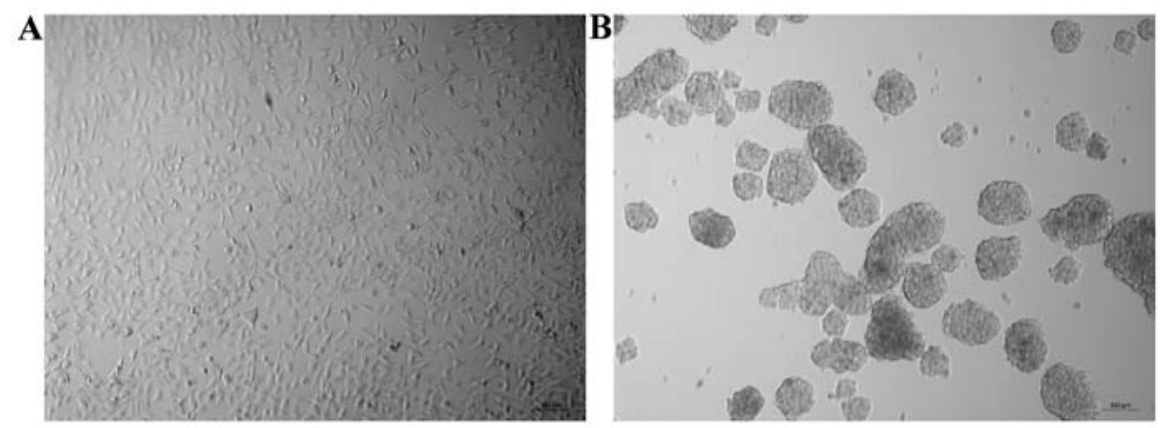

C

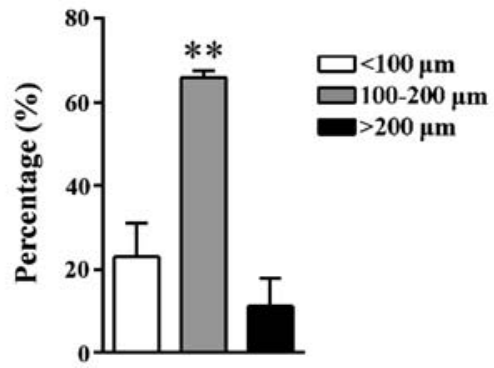

$\mathbf{D}$

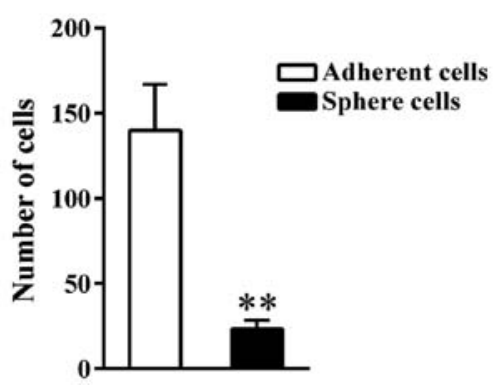

Figure 1. Morphology and LDA of A549 adherent cells and tumor sphere cells. (A) A549 cells cultured in RPMI-1640 containing 10\% FBS grew as an adherent monolayer (magnification, x100). (B) A549 cells cultured under the non-adhesive culture system formed typical tumor spheres (magnification, x100). (C) Statistical results of the diameter of spheres ${ }^{(* *} \mathrm{P}<0.01$ vs. control group with diameter $\left.<100 \mu \mathrm{m}\right)$. (D) The frequency of sphere-initiating cells was calculated based on the ELDA result. The number of cells required for the presence of one sphere-initiating cell was calculated ( ${ }^{* *} \mathrm{P}<0.01 \mathrm{vs.}$ control group). ELDA, extreme LDA; LDA, limiting dilution analysis.
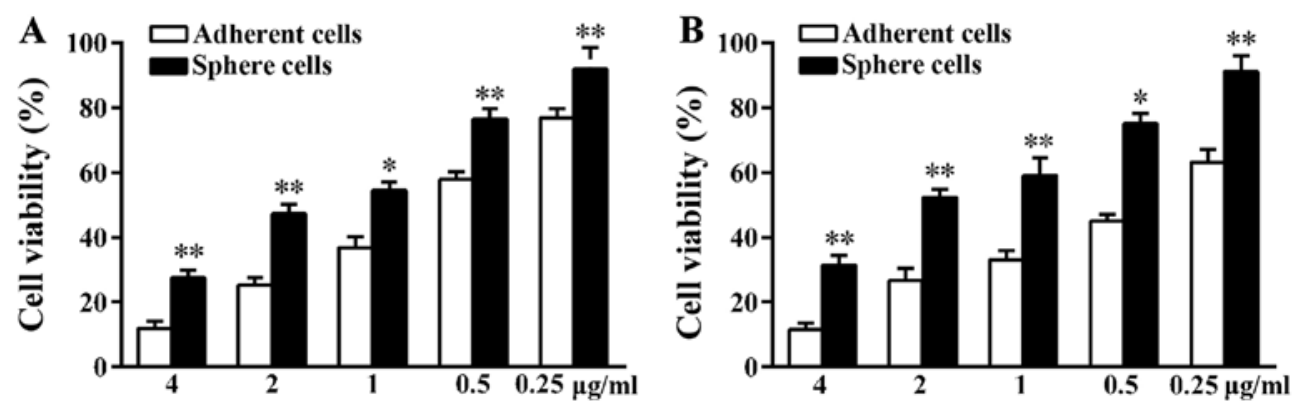

Figure 2. A549 sphere cells were more resistant to cytotoxic drugs. Cell viability assays of A549 adherent and sphere cells after treatment with (A) docetaxel and (B) cisplatin ( $\mathrm{P}<0.05$ and ${ }^{* *} \mathrm{P}<0.01$ vs. control group).

in the presence of cytotoxic drugs (15). Since the activities of $\mathrm{ABC}$ transporters on the surface of CSCs are higher than that of non-CSCs, CSCs can discharge drugs leading to tumor regenesis (16). The A549 adherent and sphere cells were treated with the same concentration of docetaxel and cisplatin for $48 \mathrm{~h}$. At the end of treatment, the MTT assay was used to validate cell viability. As shown in the results, in contrast to adherent cells, more sphere cells survived under high concentration of drugs (Fig. 2). The number of sphere cells that survived was 2.33-fold that of adherent cells when treated with $4 \mu \mathrm{g} / \mathrm{ml}$ docetaxel. When treated with $4 \mu \mathrm{g} / \mathrm{ml}$ cisplatin, the number of sphere cells that survived was 2.73 -fold that of adherent cells. Tumor sphere cells showed higher chemoresistance ability compared to adherent cells suggesting more CSCs were in the sphere cells.

Migration ability of sphere cells is higher than that of adherent cells. CSCs are the main cause of tumor metastasis $(3,17)$. The cell invasion assay was used to compare the migration capacity of A549 adherent and sphere cells. It was found that, more sphere cells migrated through the Transwell membrane than adherent cells (Fig. 3A and B). The number of adherent cells that migrated was $66.67 \pm 14.57 /$ field while the number of sphere cells that migrated was $288.67 \pm 25.11 /$ field (Fig. 3C).

Sphere cells express high levels of Oct4, Sox 2 and CD133. Oct4 and Sox 2 are two important transcription factors that are essential to embryonic stem cells $(18,19)$. Previous findings have identified that Oct 4 and Sox 2 are important in the regeneration of many CSCs (20-22). RT-PCR and IFS assays were used to validate the expression of Oct 4 and Sox 2 in the A549 spheres. The mRNA expression of Oct 4 and Sox 2 was higher in the A549 sphere cells compared to the adherent cells (Fig. 4A). In spite of the controversial studies over whether CD133 could be used as a marker for lung CSCs, the expression of CD133 was upregulated in the A549 sphere cells (Fig. 4A). Consistent with the RT-PCR assay result, Oct4 and Sox2 protein was also detected in the sphere cells colocalized with 

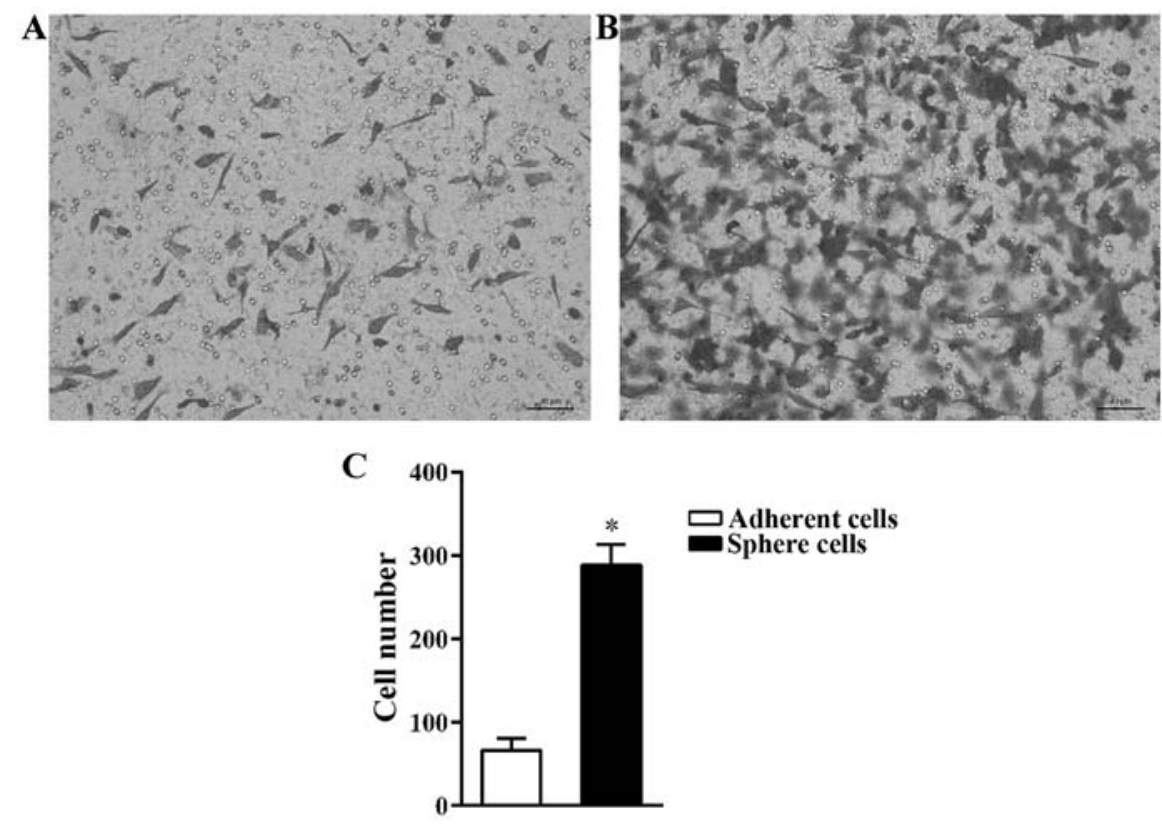

Figure 3. A549 sphere cells were more invasive than adherent cells. Invasive cells of (A) A549 adherent cells and (B) A549 sphere cells. (C) Histogram showing a significant increase in the invasive cells of A549 sphere cells (" $\mathrm{P}<0.05$ vs. control group).
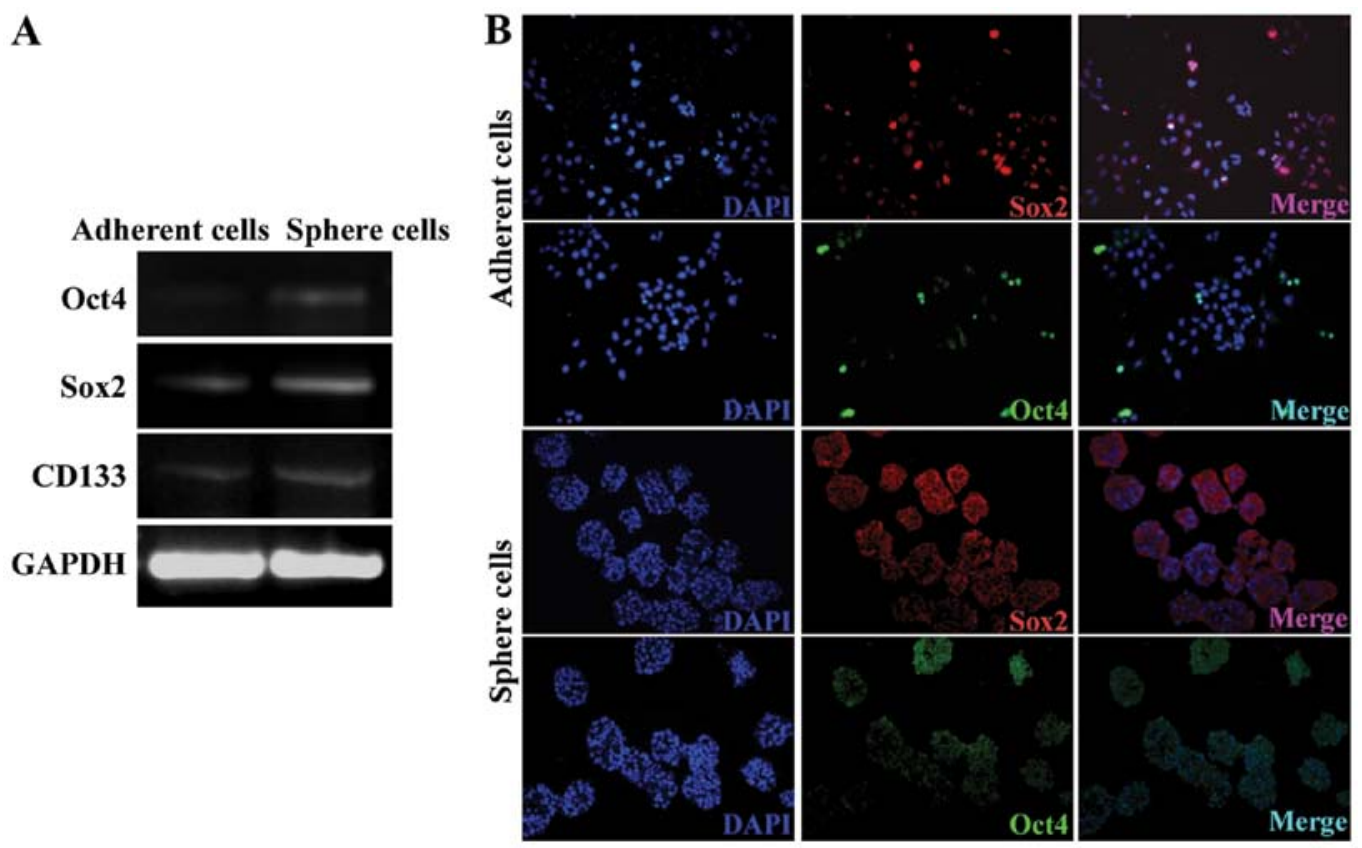

Figure 4. Expression of Oct4, Sox 2 and CD133 in A549 adherent cells and sphere cells. (A) RT-PCR analysis of genes, GAPDH was used as a loading control. (B) Immunofluorescent staining of stem cell markers, Oct4 and Sox2. Blue, DAPI-stained cell nuclei; green, expression levels of Oct4; red, expression levels of Sox2 (magnification, x200). Oct4, octamer-binding transcription factor 4; Sox2, sex-determining region Y-box 2.

the nuclei (Fig. 4B). The expression level of Oct4 and Sox 2 was not uniform among the sphere cells suggesting that the sphere cells were at different stages. Sphere cells with a low expression of Oct 4 and Sox 2 may result from the differentiation of CSCs to non-CSCs.

Sphere cells are more tumorigenic in vivo. The A549 adherent and sphere cells were subcutaneously injected into nude mice. The A549 sphere cells induced tumor when only $1 \times 10^{4}$ cells were injected into mice (one out of four mice, Fig. 5A and B).
By contrast, $1 \times 10^{5}$ parental A549 adherent cells were needed to generate tumor (one out of four mice, Fig. 5C). When $1 \times 10^{5}$ cells were injected, the sphere cells had a higher tumor formation rate (three out of four mice) than the adherent cells (one out of four mice) suggesting that A549 sphere cells were enriched with tumor-initiating cells. The histological results showed that compared to tumors derived from adherent A549 cells, tumor tissue derived from sphere cells was more compact with less space between tumor cells (Fig. 6A and B). Angiogenesis plays a critical role in the growth of tumor 
A

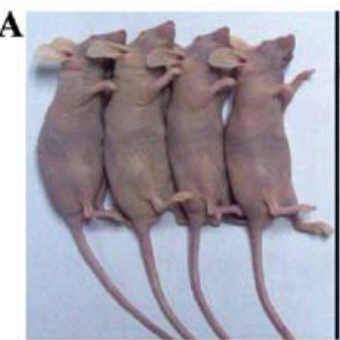

C

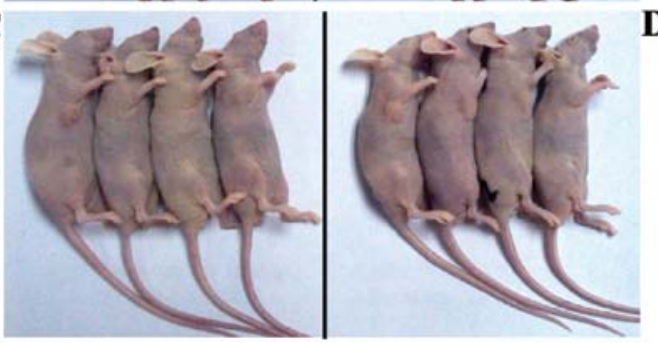

B
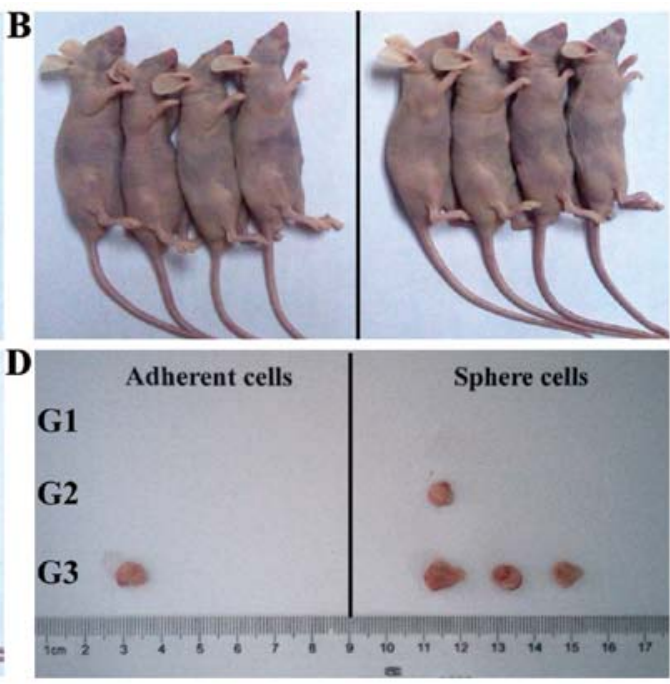

Figure 5. A549 sphere cells are more tumorigenic in vivo. (A) In group 1 (G1), $1 \times 10^{3}$ A549 adherent cells were injected in the four mice on the left, $1 \times 10^{3}$ sphere cells were injected in the four mice on the right. (B) In group 2 (G2), 1 $10^{4}$ A549 adherent cells were injected in the four mice on the left, $1 \times 10^{4}$ sphere cells were injected in the four mice on the right. (C) In group 3 (G3), $1 \times 10^{5}$ A549 adherent cells were injected in the four mice on the left, $1 \times 10^{5}$ sphere cells were injected in the four mice on the right. (D) Images of the tumors formed in each group.

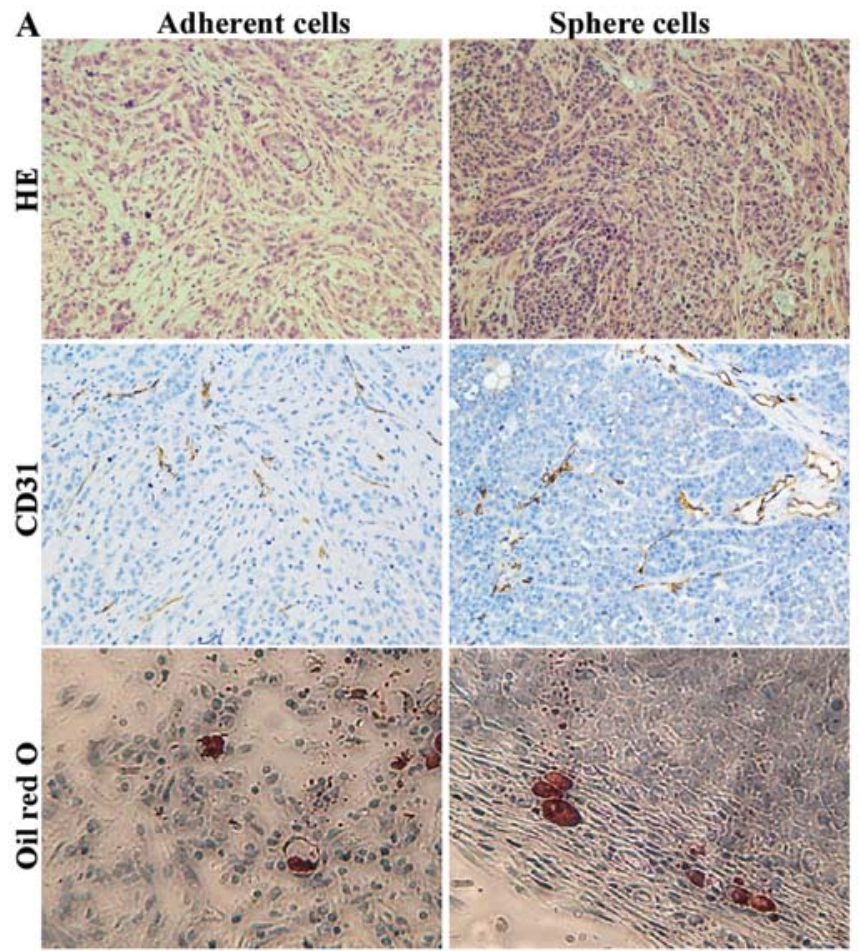

B
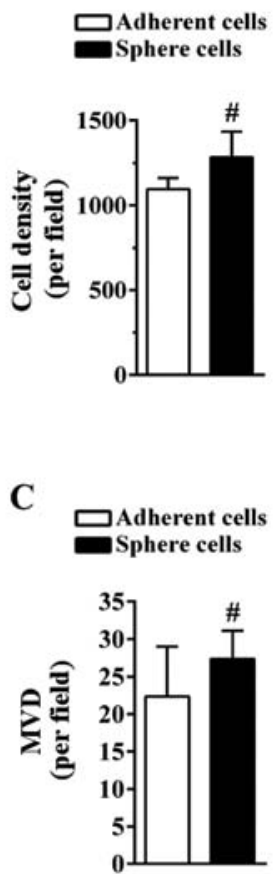

Figure 6. Comparison of the newly generated tumors between A549 adherent cells and sphere cells in mice. (A) Corresponding histological and IHC results for CD31 (magnification, x200) and Oil red O staining of the tumor tissues (magnification, x400). (B) Histogram showing that the tumor tissue derived from sphere cells was more compact ( ${ }^{*} \mathrm{P}>0.1, \mathrm{P}=0.11$ vs. control group). (C) The MVD of tumors counted by $\mathrm{CD} 31$ immunostaining $\left({ }^{*} \mathrm{P}>0.1, \mathrm{P}=0.32\right.$ vs. control group). HE, hematoxylin and eosin staining. IHC, immunohistochemistry.

by supplying tumor cells with necessary oxygen and nutrients. Blood vessels were formed in the two tumor tissues as indicated by the CD31-positive area (Fig. 6A). The MVD of tumors derived from adherent cells was $22.33 \pm 6.66 /$ field while the MVD of tumors generated from sphere cells was $27.33 \pm 3.79 /$ field (Fig. 6C). The presence of more CSCs in sphere cells may lead to the formation of more blood vessels. Certain CSCs still maintain the ability to differentiate into multiple types of cells (23). Intracellular lipid vesicles were detected on the edge of the two tumor tissues as shown in the Oil red $\mathrm{O}$ staining, suggesting the in vivo differentiation ability of A549 sphere cells into adipocytes (Fig. 6A).

\section{Discussion}

The CSCs theory sheds light on the origin of tumor, tumor development, metastasis, relapse and drug resistance. Therefore, the establishment of a reliable and efficient model 
of enriching CSCs is necessary for basic and clinical research. Compared to other methods, the non-adhesive culture system holds great advantage as it does not require the specific surface markers or chemical drugs (24). In this study, human NSCLC stem-like cells were enriched by the A549 cell line using the non-adhesive culture system. To the best of our knowledge, this was the first study involving the enrichment of A549 CSCs using this method.

The transcription profiles of some high-grade tumors and stem cells (SCs) are similar (25). The expression of transcription factors Oct4 and Sox2, which were essential to maintain the pluripotency of stem cells was upregulated in the sphere cells. The similarity between SCs and CSCs suggested that important signaling pathways may be shared. Our results also show that CD133 expression was upregulated in sphere cells suggesting that $\mathrm{CD} 33^{+}$cells were enriched in A549 sphere cells. There has been controversy regarding whether CD133 can be used as the lung CSCs marker, which may result from the interchange between CSCs and differentiated tumor cells as suggested by the stochastic model (26). In addition, it has been found that sorted $\mathrm{CD}_{133^{+}}$and $\mathrm{CD} 133^{-}$cells are capable of regenerating $\mathrm{CD}_{133^{+}}$and $\mathrm{CD} 133^{-}$cells (7). Considering the heterogeneity of lung cancer, CD133 alone may not be sufficient for the identification of lung CSCs.

The tumorigenic ability of sphere cells was confirmed in vivo. In contrast to A549 adherent cells, fewer sphere cells were needed to generate tumor in mice. More blood vessels were detected in the tumors derived from sphere cells. It is a complex and bidirectional interaction between CSCs and the blood vessels around them. In a previous study it was found that brain tumor CSCs can promote blood vessel formation by secreting VEGF (27). Since CSCs depend on the blood vessel to supply oxygen and nutrients, angiogenesis inhibitors such as bevacizumab have been used in combination with chemotherapeutic drugs in the treatment of lung cancer (28). The intracellular lipid vesicles detected in the tumor tissue suggested the differentiation potential of sphere cells in vivo. The induction of lung CSCs to adipogenic cells in vitro has been reported (29). Induction of the differentiation of CSCs to non-tumorigenic cells that are vulnerable to chemotherapeutic drugs is a new option in the treatment of lung cancer (30).

In conclusion, the human NSCLC stem-like cells were successfully enriched by the A549 cell line using the non-adhesive culture system. Sphere cells exhibited the characteristics of CSCs in vitro and in vivo and may be used as a model for screening substances targeting CSCs for the preclinical research of human NSCLC. Combined therapy targeting different signaling pathways of CSCs may achieve a better clinical outcome considering the characteristics of CSCs.

\section{Acknowledgements}

We would like to thank Professor Jialiang $\mathrm{Hu}$ for the valuable suggestions during the writing of the manuscript. This study was supported by the 863 High-Technology Development Planning (no. SQ2011SF11B02030), the Project Program of the State Key Laboratory of Natural Medicines (no. SKLNMBZ201403) and the National Science and Technology Major Projects of New Drugs (nos. 2012ZX09103301-004 and 2014ZX09508007) in China.

\section{References}

1. Medema JP: Cancer stem cells: The challenges ahead. Nat Cell Biol 15: 338-344, 2013.

2. Beck B and Blanpain C: Unravelling cancer stem cell potential. Nat Rev Cancer 13: 727-738, 2013.

3. Li S and Li Q: Cancer stem cells and tumor metastasis (Review). Int J Oncol 44: 1806-1812, 2014.

4. Tang DG: Understanding cancer stem cell heterogeneity and plasticity. Cell Res 22: 457-472, 2012.

5. Larzabal L, El-Nikhely N, Redrado M, Seeger W, Savai R and Calvo A: Differential effects of drugs targeting cancer stem cell (CSC) and non-CSC populations on lung primary tumors and metastasis. PLoS One 8: e79798, 2013.

6. Eramo A, Lotti F, Sette G, Pilozzi E, Biffoni M, Di Virgilio A, Conticello C, Ruco L, Peschle C and De Maria R: Identification and expansion of the tumorigenic lung cancer stem cell population. Cell Death Differ 15: 504-514, 2008.

7. Meng X, Li M, Wang X, Wang Y and Ma D: Both $\mathrm{CD}_{133^{+}}$and CD133- subpopulations of A549 and H446 cells contain cancer-initiating cells. Cancer Sci 100: 1040-1046, 2009.

8. Cui F, Wang J, Chen D and Chen YJ: CD133 is a temporary marker of cancer stem cells in small cell lung cancer, but not in non-small cell lung cancer. Oncol Rep 25: 701-708, 2011.

9. Akunuru S, James Zhai Q and Zheng Y: Non-small cell lung cancer stem/progenitor cells are enriched in multiple distinct phenotypic subpopulations and exhibit plasticity. Cell Death Dis 3: e352, 2012.

10. Tirino V, Desiderio V, Paino F, De Rosa A,Papaccio F, La Noce M, Laino L, De Francesco F and Papaccio G: Cancer stem cells in solid tumors: An overview and new approaches for their isolation and characterization. FASEB J 27: 13-24, 2013.

11. Roudi R, Madjd Z, Ebrahimi M, Samani FS and Samadikuchaksaraei A: CD44 and CD24 cannot act as cancer stem cell markers in human lung adenocarcinoma cell line A549. Cell Mol Biol Lett 19: 23-36, 2014.

12. Wang L, Guo H, Lin C, Yang L and Wang X: Enrichment and characterization of cancer stem like cells from a cervical cancer cell line. Mol Med Rep 9: 2117-2123, 2014.

13. Chen SF, Chang YC, Nieh S, Liu CL, Yang CY and Lin YS: Nonadhesive culture system as a model of rapid sphere formation with cancer stem cell properties. PLoS One 7: e31864, 2012.

14. Cheng HH, Kuo CC, Yan JL, Chen HL, Lin WC, Wang KH, Tsai KK, Guvén H, Flaberg E, Szekely L, et al: Control of cyclooxygenase- 2 expression and tumorigenesis by endogenous 5-methoxytryptophan. Proc Natl Acad Sci USA 109: 13231-13236, 2012.

15. Niero EL, Rocha-Sales B, Lauand C, Cortez BA, de Souza MM, Rezende-Teixeira P, Urabayashi MS, Martens AA, Neves JH and Machado-Santelli GM: The multiple facets of drug resistance: One history, different approaches. J Exp Clin Cancer Res 33: 37, 2014.

16. Di $\mathrm{C}$ and Zhao Y: Multiple drug resistance due to resistance to stem cells and stem cell treatment progress in cancer (Review). Exp Ther Med 9: 289-293, 2015.

17. Singh A and Settleman J: EMT, cancer stem cells and drug resistance: An emerging axis of evil in the war on cancer. Oncogene 29: 4741-4751, 2010.

18. Tay Y, Zhang J, Thomson AM, Lim B and Rigoutsos I: MicroRNAs to Nanog, Oct 4 and Sox 2 coding regions modulate embryonic stem cell differentiation. Nature 455: 1124-1128, 2008.

19. Takahashi K and Yamanaka S: Induction of pluripotent stem cells from mouse embryonic and adult fibroblast cultures by defined factors. Cell 126: 663-676, 2006.

20. Nakatsugawa M, Takahashi A, Hirohashi Y, Torigoe T, Inoda S, Murase M, Asanuma H, Tamura Y, Morita R, Michifuri Y, et al: SOX2 is overexpressed in stem-like cells of human lung adenocarcinoma and augments the tumorigenicity. Lab Invest 91: 1796-1804, 2011.

21. Beltran AS, Rivenbark AG, Richardson BT, Yuan X, Quian H, Hunt JP, Zimmerman E, Graves LM and Blancafort P: Generation of tumor-initiating cells by exogenous delivery of OCT4 transcription factor. Breast Cancer Res 13: R94, 2011.

22. Ling GQ, Chen DB, Wang BQ and Zhang LS: Expression of the pluripotency markers Oct $3 / 4$, Nanog and Sox 2 in human breast cancer cell lines. Oncol Lett 4: 1264-1268, 2012.

23. Liu H, Zhang W, Jia Y, Yu Q, Grau GE, Peng L, Ran Y, Yang Z, Deng $H$ and Lou J: Single-cell clones of liver cancer stem cells have the potential of differentiating into different types of tumor cells. Cell Death Dis 4: e857, 2013. 
24. Tirino V, Desiderio V, Paino F, Papaccio G and De Rosa M: Methods for cancer stem cell detection and isolation. Methods Mol Biol 879: 513-529, 2012.

25. Li Y and Laterra J: Cancer stem cells: Distinct entities or dynamically regulated phenotypes? Cancer Res 72: 576-580, 2012.

26. Plaks V, Kong N and Werb Z: The cancer stem cell niche: How essential is the niche in regulating stemness of tumor cells? Cell Stem Cell 16: 225-238, 2015.

27. Borovski T, De Sousa E Melo F, Vermeulen L and Medema JP: Cancer stem cell niche: The place to be. Cancer Res 71: 634-639, 2011.
28. Twelves C, Chmielowska E, Havel L, Popat S, Swieboda-Sadlej A, Sawrycki P, Bycott P, Ingrosso A, Kim S, Williams JA, et al: Randomised phase II study of axitinib or bevacizumab combined with paclitaxel/carboplatin as first-line therapy for patients with advanced non-small-cell lung cancer. Ann Oncol 25: 132-138, 2014.

29. Zakaria N, Yusoff NM, Zakaria Z, Lim MN, Baharuddin PJ, Fakiruddin KS and Yahaya B: Human non-small cell lung cancer expresses putative cancer stem cell markers and exhibits the transcriptomic profile of multipotent cells. BMC Cancer 15: 84, 2015.

30. Wu X, Chen $\mathrm{H}$ and Wang X: Can lung cancer stem cells be targeted for therapies? Cancer Treat Rev 38: 580-588, 2012. 